\title{
La mujer en la prensa aragonesa. Análisis de los periódicos de referencia
}

\author{
Women in the aragonese press. Analysis of the referential newspapers.
}

\author{
Dra. María Gómez y Patiño \\ Universidad de Zaragoza (España) \\ www.unizar.es
}

Recibido: 01 de diciembre 2012 Aceptado: 27 de diciembre 2012

\section{Resumen}

Este artículo expone el análisis del tratamiento periodístico que la prensa aragonesa da al issue "mujer" el Día Internacional de las Mujeres. Se aborda desde cuatro ángulos: 1) Descripción y medición del espacio dedicado, comparativamente, -cuantitativo-; 2) Análisis del tratamiento lingüístico y periodístico -cualitativo-; y 3) Análisis de la Agenda Setting y la convergencia periodístico-política.

La suma de lo cuantitativo y lo cualitativo arroja unos resultados que junto con los efectos de la formación de la agenda periodística permiten conocer la posición de la mujer en los periódicos El Heraldo de Aragón y El Periódico de Aragón.

\section{Abstract}

This article shows the analysis of the journalistic treatment that aragonese press devotse to the issue "women" during the Women's International Day. This study focuses on four angles: 1) description and quantification of the space given in a comparative way -quantitative-; 2) analysis of the linguistic and journalistic treatment of the subject -qualitative-; 3) analysis of the Agenda Setting and its journalistic and political convergence.

The conjunction of qualitative and qualitative characteristics together with the effects produced by the journalistic agenda allow to come to the final results and know the position of 'women' within El Heraldo de Aragón y El Periódico de Aragón.

Palabras Clave: Género, Agenda setting, efectos de los medios, Día Internacional de las Mujeres.

Key Words: Gender, Agenda setting, Mass media effects, Women's International Day. 


\section{Introducción}

Los medios de comunicación no son ajenos a la realidad social. Todo lo contrario, son los notarios y relatores de la realidad social y por tanto actúan como un reflejo tanto de los acontecimientos como del sentir popular. Dado que los medios cubren sólo y exclusivamente los temas de interés público o general, éstos constituyen un termómetro muy valioso, de una parte, para describir y conocer la realidad social (Berger Y Luckmann, 1989; Hernando, 1990), de una forma documentable, y de otra, para hacer que los temas narrados en ellos se conviertan a su vez en el repertorio de temas que le interesan o preocupan a la opinión pública, a ese mente pública. Estoy muy de acuerdo con la afirmación de López-Escobar, Llamas Y Mccombs (1996) cuando dicen que los medios van creando un espacio para la reflexión común y también que los medios transmiten a sus audiencias la relevancia y jerarquización de los temas que se perciben como importantes. Siendo este hecho crucial, en el planteamiento de esta investigación surgía otra pregunta que era: si la agenda de políticas públicas es una y es recogida en las agendas periodísticas, ¿existiría alguna diferencia en su cobertura y en tratamiento periodístico, especialmente en su jerarquización, elegida y aplicada por un periódico de corte conservador El Heraldo de Aragón, frente a un periódico de corte más progresista, El Periódico de Aragón en la misma ciudad, Zaragoza? Se decidió elegir y analizar un día especial en un año particular: el Día Internacional de las Mujeres Trabajadoras, el 8 de marzo de 2007 (en adelante 8-M), por ser éste el Año Europeo de la Igualdad, coincidencia que merecía una atención especial, en cuya víspera, el 7-3-2007 fue aprobada la Ley de Igualdad, calificada como muy avanzada en el ámbito jurídico europeo e internacional. El hecho de que se le otorgue al tema de la mujer trabajadora un día conmemorativo a nivel internacional y que se organicen infinidad de actos, eventos, reuniones, celebraciones, etc., informan de la naturaleza y de la importancia del tema.

Las agendas periodísticas además de ir configurando la opinión pública, van también configurando la idea que los propios ciudadanos tienen de los temas que forman parte de la agenda política. En el tema elegido, el Día Internacional de las Mujeres Trabajadoras, cabe preguntarse si se trata de una noticia; de efemérides; de un item de la agenda periodística y política; o un ítem emergente, temporal y abierto.

Esta investigación trata de ofrecer una visión objetiva del tema analizando exclusivamente "lo publicado" en torno a la mujer, en su día internacional en la prensa aragonesa, y más concretamente en los periódicos de referencia en la Comunidad Autónoma de Aragón, que se publican en su capital, Zaragoza, y que son El Heraldo de Aragón y El Periódico de Aragón.

El propio día, su celebración y el espacio ocupado en los medios podría ser un ítem de la agenda periodística obligada profesionalmente a cubrir la celebración dándole el contenido propio del día. Por otra parte rememorar un acontecimiento que sucedió años atrás podría ser considerado como una efeméride, dado que por ésta se suele entender un 
acontecimiento noticiable que se reactiva en todos los aniversarios del mismo, o simplemente la celebración de dicho aniversario. Tanto en un caso como en otro se puede hablar de discurso periodístico, (Van Dijk, 1990) para definir todo aquel texto, cualquiera que sea su naturaleza, contenido en el medio impreso (Balle, 1991), y el discurso periodístico trata el tema "mujer", lo cual no implica que el discurso periodístico tenga un estilo feminista. En este sentido apostilla Dader (2000:24) que: "El que haya noticias sobre mujeres o presencia femenina en la selección informativa no significa necesariamente que la perspectiva o discurso que se utilice para narrar tales presencias haya modificado el dominante discurso andrógino...".

El día y el discurso elegidos son una gran excepción. En modo alguno existe tal despliegue informativo con presencia femenina en la prensa diaria. Obviamente se trata de una conmemoración muy especial, tanto por el día como por el año.

\section{Objetivos}

El objetivo de este trabajo es poder dar respuesta a la pregunta: ¿Cuál es la posición de los periódicos (diarios) aragoneses de referencia frente al 8-M? Poder describir el posicionamiento de la prensa aragonesa significa poder conocer también la opinión pública aragonesa, dada la estrecha y necesaria relación entre lo publicado y la opinión pública. El objeto de estudio lo son por tanto los dos diarios aragoneses de referencia, edición Zaragoza, dado que esta ciudad no sólo es la capital política de la Comunidad Autónoma de Aragón, sino que demográficamente es más importante que las otras dos provincias juntas: Huesca o Teruel. Se analizan por tanto los diarios correspondientes al 8 de marzo de 2007, alfabéticamente relacionados, y que son: (1) El Heraldo de Aragón y (2) El Periódico de Aragón.

\section{Los espacios analizados son:}

1) Portada o Primera Página.

2) Editorial y/o Opinión

3) Sección o cuadernillo especial dedicado al 8 de Marzo 2007.

4) Páginas de Sociedad

5) Páginas de Trabajo y Economía

6) Cartas al Director

7) Información General

No se consideraron secciones como cuadernillos o suplementos literarios dado que entrañaba una gran dificultad poder dirimir si el tema Mujer, era casual o voluntariamente relacionado con el $8-M$. Por otra parte, el jueves es el día del suplemento literario en El 
Heraldo de Aragón, con lo que los resultados del análisis habrían estado distorsionados de partida.

Ciertamente la noción de noticia es ambigua. Si tendemos a pensar que el concepto general de noticia es la información nueva, no es tal el hecho de que se celebre el Día Internacional de las Mujeres. En cambio si es noticia el contenido de los temas tratados este día. Dicho de otra forma, la información ofrecida es nueva y relativa a sucesos recientes con él vinculados, y por consiguiente, podría afirmarse que se trata de una noticia ${ }^{1}$.

\section{Corpus de Investigación}

La selección del corpus para la investigación, la recogida de material, su posterior análisis y evaluación ha posibilitado tener una visión ajustada a la realidad social del objeto estudiado, es decir, los medios de comunicación impresos, o periódicos diarios, que es un material documentable, cuyo análisis ofrece resultados contrastables y verificables. Este corpus está claramente acotado y delimitado según los criterios expuestos anteriormente y está constituido por los artículos relacionados a continuación, debidamente numerados y clasificados para su total identificación y localización, cuyos títulos se exponen a continuación:

\subsection{El Heraldo de Aragón - 8 de marzo, 2007}

- La ONU pide el fin de la impunidad de la violencia contra mujeres y niñas.

- Por la igualdad real.

- La ONU pide el fin de la impunidad de la violencia contra mujeres y niñas.

- "Miss España no quiere ser la que cambie las reglas"?.

- Actos en Aragón

- Un día para todas las mujeres no es suficiente

- Poner fin a la violencia contra mujeres y niñas.

\subsection{El Periódico de Aragón - 8 de marzo, 2007}

- La presencia de la Mujer en la Historia de las Ciencias.

- Aragón, pionera en promover la igualdad.

- España invertirá 490 millones al año en lograr la igualdad de sexos.

- EI PSOE se suma al acuerdo de alargar la baja a las madres de prematuros.

- La mujer tiene más estudios pero gana un $15 \%$ menos.

\footnotetext{
${ }^{1}$ Para mayor claridad sobre la comprensión, estructura y producción de la información, véase La noticia como discurso, de Teun A. Van Dijk.

${ }^{2}$ Las comillas figuran en el propio titular del periódico.
} 
- La discapacidad y el desempleo.

- "Las empresas aún ponen pegas a las madres"3.

- Día de la Mujer Trabajadora.

\section{Metodología}

Este estudio se aborda desde dos perspectivas: cuantitativa y cualitativa, (Ibáñez, 1990; Conde, 1990) añadiendo el análisis de temas tan cruciales en la creación de la opinión pública como la agenda-setting (Mccombs \& SHAW, 1972). Cuantitativamente se describe y mide el espacio, sus características que se comparan. Cualitativamente: se analiza el tratamiento lingüístico (Bardin, 1986) y periodístico de los diferentes artículos que componen el corpus, con especial incidencia en el giro lingüístico en ciencias sociales, lo que ha permite evaluar la sensibilidad del medio hacia el tema.

Conviene aclarar en este punto que la gran riqueza lingüística (Greimas, 1980; BLANCO Y BUENO, 1983) viene determinada por la autoría del artículo, su sensibilidad, su estilo escribiendo, su pertenencia al medio, su ideología (Aguilera, 1990) o su actitud personal o profesional ante el tema. Todo ello se puede escudriñar siempre que no se trate de un texto elaborado por una agencia, de la forma más neutra posible para su utilización en todos los medios de comunicación indistintamente. En ese caso, esa riqueza diferenciadora no es traceable, y no se debe olvidar que una parte nada desdeñable de los medios impresos se hace sobre la base de noticias de agencia lo que dificulta su valoración. No debe olvidarse que en periodismo, la forma es el fondo. Cabe deducir por tanto, que la actitud que un medio manifiesta hacia un tema la pone de manifiesto cuando jerarquiza, selecciona y trata el texto de una forma concreta: en una u otra página (par o impar), con uno u otro espacio, con una o ninguna fotografía, con la creación de un cuadernillo monográfico, etc. En ocasiones el posicionamiento es tan visible y evidente que ni siquiera se necesita recurrir a analizar los giros socio-lingüísticos, y el mero análisis del tratamiento periodístico formal ofrece un posicionamiento inequívoco. Aunque siempre es deseable una coherencia entre la forma y el contenido, no es siempre exacta. Mucho del lenguaje periodístico viene determinado por la utilización de los recursos, no sólo de redacción periodística, sino de tratamiento periodístico.

Por esta razón, las noticias -no firmadas- no se analizaron socio-lingüísticamente dado que no aportan elemento diferenciador alguno, mientras que sucede todo lo contrario con las fotografías. Así, mientras que el análisis cuantitativo arroja un tipo de información de base socio-estadística, el cualitativo lo hace de forma sociolingüística.

En lo relativo a la Agenda Setting, con este concepto se alude al establecimiento de la agenda periodística, que frece un tipo de información que permite deducir las razones de la

\footnotetext{
${ }^{3}$ Ibidem.
} 
selección temática, en función también de las agendas políticas, de los temas emergentes y de las ideologías subyacentes. Como afirmaba Robert Ezra Park, uno de los miembros más relevantes de la Escuela de Chicago (1920-30) en Dader (1992) la jerarquización de los temas ofrecidos al público, estaba en manos del poder o de la agenda política. Por ello, la fijación de la agenda periodística para cada medio de comunicación, ha permitido ver la convergencia o divergencia existente con las agendas políticas. En cuanto a las secuencias temporales de la producción de las diferentes agendas, ha resultado muy esclarecedor el hecho de poder establecer una convergencia de las agendas política y periodística. A mayor coincidencia, más próximo resulta el concepto del tiempo óptimo de coincidencias de agendas (OES - Optimal effect span).

\subsection{Parámetros cuantitativos}

Se estableció aquí una relación descriptiva de todos aquellos elementos externos y de presentación de la noticias, porque el tratamiento de los espacios, la inserción de las noticias en secciones concretas, la forma de diagramar una página, las líneas dedicadas al título, antetítulo o subtítulo, el número de páginas o su porcentaje dedicado a una noticia permiten calibrar la importancia que el periódico le confiere, generando así una suerte de socioestadística (García Ferrando, 1995). Aspectos formales como su inclusión en una página par o impar tiene un efecto y una consideración distinta, de la misma forma que presentar o no una fotografía o un despliegue gráfico importante hablan de la relevancia del tema periodística y socialmente hablando. El debate causa-efecto sobre si los medios de comunicación reflejan la sociedad, o es la sociedad la que toma sus patrones sociales de los medios de comunicación, aunque no pueda ser resuelto claramente, no puede negarse la relación existente, resultando que la descripción detallada de los contenidos mediáticos ofrece una visión muy afinada de la importancia que cada medio confiere al tema. Por ello, se describen aspectos formales como el número de página en el que aparece (par o impar), nombre de la sección, parte superior o inferior de la página, el número de columnas que ocupa el texto, si está acompañado de una fotografía o cualquier otro tipo de ilustración gráfica. Igualmente es muy significativo que un artículo esté firmado o no, con antetítulo y/o subtítulo o sin él, algún destacado, y el número de líneas que ocupa así como el número de columnas, o el porcentaje que la noticia representa en la página concreta o si está tipográficamente destacado. Todos estos aspectos formales, necesariamente presentes en el tratamiento periodístico de cualquier medio impreso son muy significativos para cualquier profesional de medios o analista de estos, pero resultan difícilmente observables por el lector común de prensa escrita.

Se presenta aquí un cuadro-resumen de elaboración propia que muestra las diferencias claramente, pudiendo ser evaluadas de una sola mirada. 


\subsubsection{Cuadros resumen individualizados}

\section{A) El Heraldo de Aragón - Cuadro Resumen}

\begin{tabular}{||c|c|c|c|c|c|c|c||}
\hline \hline Título & Sección & Página & Foto/Dib. & Columnas & $\%$ Pág, & Color & Tipografía \\
\hline $\begin{array}{c}\text { La ONU pide el fin de la } \\
\text { imp... }\end{array}$ & 1a Página & 1 & - & 1 & 5 & - & recuadro \\
\hline Por la Igualdad real & Tribuna & 30 & - & 2 & 20 & - & recuadro \\
\hline $\begin{array}{c}\text { La ONU pide fin de la } \\
\text { impune }\end{array}$ & $8-\mathrm{M}$ & 51 & Sí & 4 & 50 & Sí & - \\
\hline $\begin{array}{c}\text { Miss España no quiere } \\
\text { ser ... }\end{array}$ & $8-\mathrm{M}$ & 51 & Sí & 4 & 20 & Sí & - \\
\hline Actos en Aragón & $8-\mathrm{M}$ & 51 & - & 1 & 10 & - & negritas \\
\hline $\begin{array}{c}\text { Un día para todas las } \\
\text { mujeres... }\end{array}$ & $8-\mathrm{M}$ & 56 & Sí & 5 & 85 & Sí & Des/neg. \\
\hline $\begin{array}{c}\text { Poner fin a la violencia } \\
\text { contra... }\end{array}$ & $8-\mathrm{M}$ & 57 & Sí & 5 & 90 & Sí & Des/neg. \\
\hline \hline
\end{tabular}

Elaboración propia

Total núm. Artículos: $\quad 7$

Art. en páginas impares: $\quad 5$

Art. en páginas pares: $\quad 2$

Art. Primera página: $\quad 1$

Suma № de páginas: $\quad 2,80$

Publicidad: $\quad 0$

Sección especial 1

Fotos/Dib./Gráficos $\quad 4$

B) El Periódico de Aragón - Cuadro Resumen

\begin{tabular}{||c|c|c|c|c|c|c|c||}
\hline \hline Título & Sección & Página & Foto/Dib. & Columnas & $\%$ Pág, & Color & Tipografía \\
\hline $\begin{array}{c}\text { La presencia de la Mujer } \\
\ldots\end{array}$ & I+DEAR & 2 & No & 1,5 & 40 & - & Negrita \\
\hline $\begin{array}{c}\text { Aragón, pionera en } \\
\text { promover.. }\end{array}$ & I+DEAR & 2 & Sí & 2 & 10 & - & Negrita \\
\hline $\begin{array}{c}\text { España invertirá 490 } \\
\text { mill... }\end{array}$ & Sdad/8-M & 39 & Sí & 2 & 70 & - & Negrita \\
\hline $\begin{array}{c}\text { El PSOE se suma al } \\
\text { acuerdo... }\end{array}$ & Sdad/8-M & 39 & Sí & 2 & 10 & - & Negrita \\
\hline $\begin{array}{c}\text { La mujer tiene más } \\
\text { estudios... }\end{array}$ & Sdad/8-M & 39 & Sí & 1 & 15 & - & Negrita \\
\hline \hline
\end{tabular}




\begin{tabular}{||c|c|c|c|c|c|c|c||}
\hline \hline $\begin{array}{c}\text { La discapacidad y el } \\
\text { desempleo }\end{array}$ & $\begin{array}{c}\text { So } \\
\text { Discapacitad }\end{array}$ & 24 & Sí & 2 & 40 & - & - \\
\hline $\begin{array}{c}\text { Las empresas aun ponen } \\
\text { peg... }\end{array}$ & 1a Persona & 64 & Sí & 2 & 80 & Sí & Negrita \\
\hline $\begin{array}{c}\text { Día de la Mujer } \\
\text { Trabajadora }\end{array}$ & Opinión & 6 & No & 2 & 10 & - & Enmasca. \\
\hline
\end{tabular}

Elaboración propia

Total núm. Artículos:

8

Art. en páginas impares:

3

Art. en páginas pares:

5

Art. Primera página:

Suma № de páginas:

0

Publicidad:

Sección especial

Fotos/Dib./Gráficos

0

1

6

\subsection{Parámetros cualitativos}

Analizar los parámetros cualitativos desde lo que se conoce en Sociología como el giro lingüístico, obligó a examinar minuciosamente todos los elementos de sentido, desde la elección del vocabulario hasta los signos cargados de significado, lo que unido a los parámetros cuantitativos permitió extraer conclusiones definitivas y alcanzar una valoración final. Cada artículo fue analizado como una unidad de análisis, desde distintas perspectivas lingüísticas, mediante el lenguaje periodístico. Atendiendo a que éste, por su naturaleza (la celeridad marca el lenguaje), a lo que se suma la regla de oro: brevedad, concisión y claridad, no facilita una gran riqueza lingüística. En cambio sí permite analizar su actitud y su tono por su propia redacción periodística junto con la distribución de los espacios.

Bajo este epígrafe se analizaron todos aquellos aspectos, que no poseen un carácter cuantitativo y por ende, no pueden ser medidos de una forma cuantitativa. Estos parámetros permitieron responder las preguntas formuladas al comienzo de este trabajo, que se revisan a continuación.

\subsubsection{El titular}

Mención especial merecen los titulares. En redacción periodística (Enzenberger, 1974) existe un punto clave y central en la aproximación a una noticia: el lector leerá o no la noticia en función de su titular. Mediante el titular de una noticia se pueden conseguir infinidad de efectos, tales como: 
- Llamar la atención del lector.

- Presentar un título representativo de la noticia, aunque sólo sea de un ángulo.

- Manifestar la actitud (positiva de aprobación o negativa de rechazo) hacia el tema del que se esta informando.

- Buscar connotaciones o asociaciones cargadas de sentido en otro tipo de lenguaje distinto del periodístico, desde literarias a históricas, bélicas a deportivas.

- Resultar muy sintético, tratando de incluir todos los ángulos (con la ayuda del antetítulo y subtítulo habitualmente).

- Generar una sensación de equilibrio o de armonía.

- Crear complicidades o adhesiones.

- Generar efectos perversos, odiosos o adversos.

- Producir ambigüedad, confusión, incertidumbre.

- Muchos otros efectos que pueden aparecer circunstancialmente.

Es, precisamente, por todas estas posibilidades periodísticas a la hora de titular una noticia por los que hubo que detenerse de forma muy especial en los títulos. Tienen una gran capacidad sintetizadora y muestran, a veces involuntaria o inconscientemente (Stubbs, 1987) mucho de la intención, de la actitud o de la ideología de su autor.

\subsubsection{Consonancia periodística y política de las agendas}

El análisis de la canalización o de la fijación de la agenda periodística, permite ver también la "consonancia o disonancia" ("Konsonanz") (Noelle-neumann, 1973) existente con las agendas políticas, y a pesar de que no pueda existir una total comprobación positivista de su utilización, ofrece al investigador la posibilidad de aventurar ciertas inferencias sin ningún otro compromiso que el científico.

En lo relativo a las secuencias temporales de la producción de las diferentes agendas, para este trabajo resulta muy esclarecedor el hecho de poder establecer una convergencia de las agendas: la política y la periodística. En la medida de su coincidencia, se tratará de lo que se conoce como el tiempo óptimo de coincidencias de agendas (OES - Optimal effect span).

El tema de la mujer, y concretamente para el caso estudiado, podría considerarse un item emergente, de temporalidad anual y abierta, o incluso como una noticia común, ya que incorpora eventos que se están produciendo, por lo que han de ser recogidos por los medios. Es un tema crónico-acumulado ("kumulation") ${ }^{4}$ (dado que aparece cada 8 de marzo), pero no gastado, y de temporalidad anual (cada año). Es abierto porque permite la entrada y la incorporación de temas nuevos emergentes convergentes/consonantes con la efeméride. El

${ }^{4}$ Cfr. NOELLE-NEUMANN, op. cit. 
análisis de la agenda-setting informa de la posición ideológica del medio con relación a su jerarquización. El establecimiento de los temas es cada vez más importante en la fijación de cualquier agenda, y muy especialmente en las agendas periodísticas o mediáticas. Existen algunos hechos o serie de coincidencias a valorar, -casuales o programadas- donde se dan una serie de actos y eventos políticos y periodísticos coincidiendo con la celebración del 8-M.

Se puede apreciar una clara coincidencia y/o convergencia de agendas. En el ámbito nacional, la agenda política incluía para este tema la aprobación de la ley de Igualdad precisamente la víspera del 8-M, y la celebración del evento político-social más importante del día, coincide con el interés de los medios de comunicación impresos en cubrir la efeméride de forma extraordinaria. En esta ocasión, la celebración del 8-M contaba con la presencia de la Reina. La agenda política tiene una perfecta cobertura en los periódicos porque los temas de la agenda política/pública han de ser parte de la agenda periodística. No sólo se trata de una coincidencia temática sino también temporal. Se presenta un Tiempo Óptimo de coincidencia de agendas (“Optimal Effect Span"): El año internacional de la Igualdad, el Gobierno español (PSOE) celebraba la aprobación de la Ley de lgualdad, y se realizaba el un Encuentro Internacional de Mujeres España-África, con la presencia de la Vicepresidenta de Gobierno y de la Reina. Por tanto, ha de ser recogida por esta la secuencia cronológica, que se produciría así:

\section{+ Día 7 de Marzo: - Aprobación de la LEY DE IGUALDAD - II Encuentro Internacional de Mujeres España- África ${ }^{5}$. \\ + Día 8 de Marzo: - Publicación de la aprobación de la Ley de Igualdad - Celebración del 8-M}

Existe una coincidencia temporal, no sólo de una conmemoración estricta, de recuerdo, o de efeméride. El hecho de la convergencia de las agendas políticas y periodísticas confiere a la jornada una naturaleza difícil de definir a priori, pero muy rica y llena de contenido, lo que produce tiempos óptimos de coincidencias de agendas. La situación de homogeneidad no es la misma para todos los medios de difusión impresos analizados.

La lematización de las instituciones, en este caso el MTAS, la Secretaría General de Políticas de Igualdad, junto con el Instituto de la Mujer (en adelante IM), o lo que se conoce en los estudios de medios como "policy agenda" ejercen una gran influencia sobre la selección periodística de los temas.

\footnotetext{
${ }^{5}$ Este evento socio-político de gran relevancia y repercusión en la prensa escrita nacional en sus ediciones de Madrid, no tuvo cobertura alguna en la prensa aragonesa, que focalizó en mayor medida sus noticias al ámbito autonómico.
} 
La agenda política tiene una forma directa de manifestar sus ítems a través de la publicidad. El hecho de que un Ministerio tenga una partida presupuestaria para Publicidad, significa que va a cubrir el evento político de forma inequívoca. Aunque no se produjera ningún acontecimiento noticiable para la agenda periodística, la publicidad estaría presente en los medios y esa inserción de publicidad pagada tiene una repercusión directa también en los contenidos de los medios impresos: aunque sólo sea recordatorio del evento, de ahí que la publicidad no pueda desdeñarse ni ignorarse, dado que los llamados efectos publicitarios cumplen varios fines (LEÓN, 1996).

\subsection{Descripción y análisis de los artículos: su espacio y maquetación}

Los titulares poseen tal riqueza semántico que su propia relación es ya un análisis por si misma, lo que justifica la elaboración de cuadros-resumen que de una sola mirada permiten tener una idea bastante aproximada del contenido de los mismos. Además del análisis de los titulares se presenta una síntesis del contenido de cada artículo que perfila y robustece el significado esbozado en el titular.

\subsubsection{El Heraldo de Aragón - 8 de marzo, 2007}

\subsubsection{L L L ONU pide el fin de la impunidad de la violencia contra mujeres y} niñas

Consta de un sumario a una columna en primera página, situado en la parte inferior izquierda. Está recuadrado por un trazo sencillo y encabezado por el epígrafe: DIA INTERNACIONAL DE LA MUJER, destacado tipográficamente en mayúsculas. Este recuadro indica asimismo que la noticia está en la página 51 y que existe un editorial del mismo tema en página 30. Lleva además inserto el símbolo del feminismo. Ocupa el $5 \%$ de la página.

\subsubsection{Por la igualdad real}

En esta ocasión es un editorial, maquetado a una columna donde deberían ir dos columnas (Standard) y enmarcado en un cuadro de doble raya. En este recuadro vertical aparecen dos editoriales. Sólo el primero está dedicado al 8-M y ocupa el $20 \%$ de la página 30 (par) de la sección Tribuna. 
4.3.1.3. La ONU pide el fin de la impunidad de la violencia contra mujeres y niñas

Éste es un artículo integrado en la sección especial del Día Internacional de la Mujer. Está escrito a cuatro columnas: Título en dos líneas y subtítulo en una. Aparece una fotografía a color de la Reina, la Primera Ministra de Mozambique y la Vicepresidenta española, a tres columnas en posición central. Incluido en una página impar (51) en la posición principal de la página. Ocupa el $40 \%$ de la página.

\subsubsection{4. "Miss España no quiere ser la que cambie las reglas"}

Es una entrevista alusiva a las reglas discriminatorias de los concursos de belleza en España. Está en la misma página impar

(51) y está escrito a cuatro columnas en las que incluye una pequeña foto a una columna a color. Presenta un antetítulo a cuatro columnas y las preguntas están tipográficamente destacadas en negrita. Ocupa el $20 \%$ de la página.

\subsubsection{Actos de Aragón}

Se trata de una pequeña agenda del día en una página impar (51) en la que se reflejan los actos que se van a realizar durante la jornada en todo Aragón. Es una columna que ocupa todo el espacio del artículo 4.3.1.3. Precisamente la misma altura a una sola columna y ocupa el $10 \%$ de la página. Destacadas tipográficamente las provincias y las ciudades en que se realizan los actos en negrita.

\subsubsection{Un día para todas las mujeres no es suficiente}

Incluido este artículo en el Especial: Día Internacional de la Mujer Trabajadora, página 56 (par). Este especial está tipográficamente destacado en negrita y subrayado. Le antecede un antetítulo a dos líneas y le sigue un subtítulo a una línea. Tanto título, subtítulo como antetítulo escritos a cinco columnas. El $50 \%$ de esta página está dedicado a 3 fotografías a color a dos columnas cada una de ellas, con sus respectivos pies de foto. Tipográficamente lleva dos destacados en negrita entre dos columnas separados por un trazo de línea gruesa en negrita.

El 15\% restante lo ocupan unos módulos publicitarios en la parte inferior izquierda. El texto representa el $35 \%$ a cinco columnas en espacio no ocupado por las fotografías. Tiene dos destacados en negrita separados por una raya. Espacio total: $85 \%$.

\subsubsection{Poner fin a la violencia contra mujeres y niñas}


Es una página ocupada por el tema, casi en su totalidad (90\%), salvo el faldón inferior dedicado publicidad (10\%). El porcentaje restante está dedicado a esta noticia a cinco columnas, con el epígrafe del Especial / Día Internacional de la Mujer.

Lleva un antetítulo en dos líneas, a cinco columnas y un subtítulo a 3 columnas; Título a tres columnas en dos líneas. Las dos columnas restantes llevan dos fotografías a color, una sobre la otra, con sus correspondientes pies de foto (20\%).

El texto (40\%) lleva un destacado entre dos columnas y está cerrado por una fotografía horizontal a cinco columnas (25\%) de la página dedicada al tema. Es una página impar (57) y forma parte del especial del día. Total: $85 \%$. Tipográficamente resalta un destacado en negrita entre dos columnas.

\subsubsection{El Periódico de Aragón- 8 de marzo, 2007}

\subsubsection{L La presienta de la mujer en la Historia de las Ciencias}

Este artículo aparece enmarcado en un cuadernillo de CIENCIA Y TECNOLOGÍA (I+DEAR). Titulado a dos líneas y a cuatro columnas destaca tipográficamente la incorporación de la negrita entre la no-negrita del propio titular. Es un artículo firmado escrito a una columna que en el Standard sería una y media, y con una entrada destacada. Ocupa el $40 \%$ del espacio de la página 2 (par) de I+DEAR (Suplemento de Divulgación Científica, Tecnológica y de Investigación).

\subsubsection{2. $\quad$ Aragón, pionera en promover la igualdad}

Este es un artículo escrito a dos columnas en el espacio de 3 bajo la fotografía anterior e igualmente titulado, que ocupa el $10 \%$ de la página en la misma página 2 (par) de I+DEAR. Aparece una fotografía central con pie de foto en 11 líneas y a media columna. Está relacionado con el anterior aunque mantiene su autonomía.

\subsubsection{España invertirá 490 millones al año en lograr la igualdad de sexos}

La página en la que aparece este artículo y los otros dos siguientes es la número 39 (impar) de la Sección de Sociedad, con un epígrafe especial dedicado a la Celebración del Día Internacional de la Mujer, donde en la parte superior derecha aparece una pequeña fotografía a una columna de la Reina y el Rey, con un pie de foto que nada tiene que ver con 
el tema central, sino con una visita que harán a un Centro de Alzheimer, promovido por la Reina.

Presenta un título en dos líneas a cinco columnas y un subtítulo, dividido en dos, de dos líneas cada uno. Es un artículo firmado y ofrece un despliegue gráfico con datos estadísticos relativos a la Ley de Igualdad.

Esta página ocupa el $70 \%$ del espacio total y resulta muy llamativa por su diseño, consistente en un gran despliegue gráfico muy particular, que ofrece datos estadísticos plasmados en figuras y porcentajes.

\subsubsection{4. $\quad$ EI PSOE se suma al acuerdo de alargar la baja de las madres de prematuros}

Este es un pequeño artículo de la misma página 39 (impar) en dos columnas y titulado también a dos columnas. Destaca que está todo él escrito en negrita. Ocupa el 10\% del espacio de la página y está marcado superiormente por dos trazos singulares.

\subsubsection{La mujer tiene más estudios pero gana un $15 \%$ menos}

Aparece con un antetítulo: INFORME EUROPEO, y el título está en cuatro líneas de una columna. Está firmado en Bruselas y ocupa un 15\% del total de la página 39 (impar).

\subsubsection{La discapacitados y el desempleo}

Este artículo aparece en la página 24 (par) y ocupa una posición central, incorporando una fotografía a dos columnas con su pie.

Lleva un subtítulo en dos líneas y dos columnas y el texto ocupa cuatro columnas. Ocupa el $40 \%$ de la página y no está firmado. La fotografía dice que es un servicio especial

\subsubsection{7. "Las empresas aún ponen pegas a las madres”}

Este es un artículo de la última página (par) y dentro de la sección EN PRIMERA PERSONA. Es una entrevista a una mujer protagonista de discriminación. Titulado a dos columnas, bajo cuyo título aparece una fotografía vertical con pie sobrepuesto en la foto. Destaca tipográficamente la utilización de negritas y un destacado enmarcado que tiene el papel de 
síntesis. Ocupa el $80 \%$ de la página. El resto lo ocupa en la parte superior un índice y publicidad y en la parte inferior, publicidad.

\subsubsection{Día de la MujerTtrabajadora}

Este título está incluido en las CARTAS AL DIRECTOR en la página 6 (par), cuya mitad superior está dedicada a opinión. Destaca topográficamente ya que está enmascarado en gris. Ocupa dos de las cinco columnas y el título también. Ocupa el 10\% del espacio.

\section{Discusión y conclusiones}

Dada la importancia que tienen los datos numéricos, resultado de la medición de los parámetros cuantitativos, el cuadro resumen final tiene la virtualidad de sintetizar todas las noticias y de ofrecer, de una sola mirada los datos que, por sí solos, resultan absolutamente significativos y son incuestionables.

\subsection{Parámetros cuantitativos}

La cuantificación tanto de la cantidad de artículos, así como el número de artículos que se presentan en páginas pares o impares, o si el tema aparece en primera página, o si le dedican una sección especial, y si el tema está ilustrado con fotografías, ofrecen ya una descripción del despliegue periodístico que, habitualmente, está íntimamente relacionado con la importancia que se le da al tema informado. De ahí que con la presentación del cuadro-resumen que se ofrece, el analista ya tiene una buena descripción cuantitativa, que junto con los datos cualitativos, le permitirán establecer algunas conclusiones.

\section{Cuadro resumen comparativo}

\begin{tabular}{||c|c|c|}
\hline \hline periódicos & HERALDO & PERIODICO \\
\hline Total núm. Artículos & 7 & 8 \\
\hline Art. en páginas impares & 5 & 3 \\
\hline Art. en páginas pares & 2 & 5 \\
\hline Art. primera página & 1 & 0 \\
\hline Suma № de páginas & 2,80 & 2,75 \\
\hline Publicidad & 0 & 0 \\
\hline Sección especial & 1 & 1 \\
\hline Fotos/Dib./Gráficos & 4 & 6 \\
\hline
\end{tabular}

Elaboración propia

Facultad de Ciencias de la Información - Universidad de La Laguna

Avenida César Manrique, s/n; Campus de Guajara

38071 La Laguna, Tenerife (Islas Canarias - España) 
Se pueden extraer, por tanto, algunas conclusiones:

Es preciso decir que el primer y el más importante termómetro de un periódico es su PRIMERA PÁGINA. Los consejos de redacción deciden, a veces no con facilidad, los temas que irán en primera página, pero necesariamente ha de existir una jerarquización temática que se aprueba y se ejecuta. La primera página contiene los temas más importantes o las referencias a los temas que serán tratados en el interior. Como se ha sugerido en otro momento, cualquier estudiante de primer curso de Periodismo sabe que esto es así desde el plano teórico, pero desde el plano práctico a ningún lector de prensa diaria se le escapa que esto es así. Su rutina de lectura, si la tiene, ya le ha dejado ver que la primera página siempre es muy relevante y sintetizadora. Nunca iría la noticia más importante en una página interior, a una columna y en tres líneas. Dicho esto, con esta primera observación tendremos ya una primera valoración. Este cuadro-resumen-final ofrece de una sola mirada este dato. El Heraldo de Aragón (1), mientras que El Periódico de Aragón ha priorizado sus temas sin incluir El Día Internacional de las Mujeres.

Nuestro segundo indicador será el espacio absoluto dedicado en número de artículos. La prensa aragonesa estaría encabezada por El Periódico de Aragón (8), y seguida por El Heraldo de Aragón (7).

El tercer indicador es sin duda el número de páginas que han dedicado al tratamiento del tema. Este dato proviene de la suma de los porcentajes dedicados en cada artículo por página. La suma de los porcentajes arroja el número de páginas totales que todos ellos han sumado provenientes de artículos de todas las secciones generales o de secciones especialmente creadas para el 8-M. El Heraldo de Aragón 2,80) seguido de El Periódico de Aragón $(2,75)$, diferencia que no es muy significativa y no permite extraer conclusiones al respecto.

El cuarto indicador serán las imágenes. Nadie duda hoy de la importancia que las imágenes (en cualquiera de sus formas) tienen en nuestra cultura. Ciertamente hay una estrecha relación con el espacio ocupado o el número de artículos dedicados al tema. El Periódico de Aragón con 6, El Heraldo de Aragón con 4.

Un parámetro importante, que los publicistas y publicitarios suelen tener muy en cuenta es el tipo de página, si es par o impar. Está demostrado que las páginas impares tienen un mayor número de lectores, con un tiempo de lectura más largo, y éstas son las razones por las que la publicidad es más cara en páginas impares que en pares. Por ello, además de haber contemplado el número de páginas y de imágenes, conviene también observar la proporción de páginas impares frente a las pares que los medios les han dedicado al tema. Una vez más, El Heraldo de Aragón (5), El Periódico de Aragón (3). 
Otro aspecto que se convierte en un buen medidor de la importancia concedida al tema es el BLANCO y NEGRO de las fotografías o el COLOR. Lógicamente, las fotografías ordinarias, de temas comunes, van, por razones de coste especialmente, en blanco y negro $(\mathrm{B} / \mathrm{N})$. El color se destina a temas destacados. En este sentido cabe destacar también la incorporación de algunos medios al color para las fotografías de este día. Así pues El Heraldo de Aragón (4); El Periódico de Aragón (6) (publicidad excluida).

\subsection{Parámetros cuantitativos}

Bajo este epígrafe analizaremos todos aquellos aspectos, que no poseen un carácter cuantitativo y por ende, no pueden ser medidos numéricamente hablando lo que nos permitirá retomar las preguntas que formulábamos al comenzar este trabajo de investigación y, que de alguna forma, constituían el motor de la investigación, y que ahora podrán ser respondidas con datos, con certezas y con verdades irrefutables tales como son esperables de cualquier trabajo de investigación metodológicamente planteado con rigor.

En el capítulo 4, relativo a la metodología ya se han expuesto algunos de los parámetros que se evaluarán en este capítulo para llegar a las conclusiones correspondientes. Hay un aspecto clave y central que nos ha parecido más oportuno presentarlo de forma especial, ya que por sí sólo merecería una aplicación aislada y autónoma. Me refiero al título, a la forma de titular una noticia, a todo lo que el titular revela y sugiere, sintetiza y comprime (Barthes, $1969,1987)$ de una forma excepcional.

Es por todas estas posibilidades periodísticas a la hora de titular una noticia por las que nos hemos centrado de una forma muy especial en los títulos. Éstos tienen una gran capacidad sintetizadora, y muestran (Recio, 1994), a veces involuntariamente, mucho más de la intención o de la actitud de su autor, que ni el propio periodista podría imaginar jamás).

A continuación se presenta un análisis cualitativo, atendiendo a los contenidos, significados, y con una especial incidencia en los titulares que, como decíamos anteriormente, tienen mucho significado por sí mismos. ¿Qué significa titular una noticia? Quizá sea una forma de hablar, (Bourdieu, 1980), o de comunicar la información de la forma más sintética y sugerente posible (Wolf, 1994).

\subsubsection{El Heraldo de Aragón}

El primer artículo del El Heraldo de Aragón muestra una gran implicación con el tema del Día Internacional de las Mujeres y el hecho de vincularlo con la ONU le da la relevancia que adquiere cualquier tema tratado por la ONU a nivel supranacional. Tanto El Heraldo de Aragón como la ONU incorporan un tema de mujer al margen del evento 8-M; añaden 
contenido al margen del II Encuentro Internacional. Aparece en primera plana, para tratarlo más ampliamente en el interior. El hecho de incorporar en primera página el símbolo del feminismo demuestra muy a las claras la vinculación del medio con el tema de la lucha de la mujer por conseguir la igualdad, lo que le vincula igualmente con la agenda política, a pesar de que el MTAS no ha insertado publicidad en su medio.

El segundo artículo es muy reivindicativo del día y muestra una fuerte implicación con la lucha contra la mortífera violencia machista que no cesa.

El tercero es el que trata el tema de ONU de primera página con más extensión. El Heraldo de Aragón se vincula a la agenda pública de la ONU, así como a la política del MTAS, aún sin haber recibido la publicidad institucional. Es un artículo serio que denuncia y aporta algunas soluciones, como el incremento de fondos para la lucha por la igualdad.

El cuarto es un artículo, firmado, (ofrece la seguridad de no ser de agencia). El Heraldo de Aragón aprovecha la visita de la eliminada Miss España a Zaragoza para tocar el tema de la discriminación laboral femenina.

El quinto artículo incorpora la agenda de actos que tienen lugar el 8-M en las tres provincias, y al tratarse de una jornada especial, informa de los actos en cuadernillo especial.

El sexto artículo hace un recorrido histórico, como recordatorio de la situación histórica y presenta la situación laboral actual para la mujer.

El séptimo hace un despliegue fotográfico realmente impactante. Aborda el tema de la violencia contra las mujeres, lo que presenta una mayor coincidencia en el año 2007 proclamado Año Europeo por la Igualdad de Oportunidades. Es un artículo muy ponderado, hasta el punto que una sola frase sintetiza su contenido. Al invocar a la responsabilidad de todos los ciudadanos establece una mayor implicación personal del lector con el mensaje transmitido: "todos y cada uno de nosotros tenemos el deber de apoyar y mantener un entorno político y social en el que no se tolere la violencia contra las mujeres y las niñas, en el que los amigos, los familiares, los vecinos, los hombres y las mujeres intervengan para impedir que los autores de estos actos queden impunes de sus delitos".

Se trata prácticamente de lo que podría llamarse un manifiesto, con lo que éste tiene de denuncia activa y de implicación con el tema.

\subsubsection{El Periódico de Aragón}

El primer artículo analizado de El Periódico de Aragón conduce directamente a un cuadernillo especial dedicado a Ciencia y Tecnología, que al aparecer el Día Internacional de las Mujeres sirve para anunciar una exposición bibiliográfica, cuyos títulos pasarán a formar parte de un fondo de préstamos relacionados con aspectos intelectuales de las mujeres. Es 
muy estimulante comprobar que lo ha escrito un hombre. En este sentido, El Periódico de Aragón establece esta primera asociación del Día Internacional de las Mujeres con la Ciencia, asociación ésta (mujer-ciencia) que ya es un clásico en Aragón, dado que la Universidad de Zaragoza y concretamente el Seminario Interdisciplinar de Estudios de la Mujer (SIEM) nació en 1994, y el tema de la mujer en la ciencia es una constante en Aragón. Por otra parte, este primer artículo es el antecesor natural del siguiente, donde El Periódico de Aragón camina por el mismo sendero, como se puede ver a continuación.

Este segundo artículo continúa en la misma línea, ampliando la misma información. En esta ocasión se destaca el hecho de que Aragón es pionera en promover la igualdad nuevamente desde el punto de vista científico, puesto que se trata de una Comisión Asesora de Mujer y Ciencia, presidida por la Consejera de Ciencia, Tecnología y Universidad: Angela Abós, cuyo objetivo es equiparar a hombres y mujeres en éste ámbito e incluso en aspectos, no poco importantes, como los retributivos.

El tercer artículo, firmado por un tándem periodístico mujer-hombre se centra en los aspectos presupuestarios que implica la aplicación de la Ley de Igualdad. El Periódico de Aragón afronta el tema desde el punto de vista presupuestario lo que resulta muy oportuno, dado que permite al lector que sea más consciente y responsable de lo que significa la aplicación de una ley de carácter social con dotación presupuestaria. Es muy positivo el verbo que utiliza para el presupuesto de 490 millones de euros no es de gasto, sino de inversión, lo que le otorga un sentido absolutamente fértil y favorable (con recuperación y beneficios) y no un gasto estéril. Por otra parte, ofrece uno de los mejores resúmenes de la ley. Está tan bien redactado, resumido y estructurado, tanto que hace prácticamente innecesario leer la Ley para conocer su esencia y filosofía.

El cuarto artículo, titulado "EI PSOE se suma al acuerdo de alargar la baja a las madres de prematuros", hace una presentación del tema en un tono altamente positivo. Ciertamente éste era un aspecto que inicialmente no había sido contemplado por la ley, pero que, al ser propuesto el PSOE automáticamente aprobó la moción sin dilación y sin poner trabas, como quizá algunos grupos políticos habían pensado. Es la voluntad de aprobar la ley lo que el titular pone de manifiesto, lo que es muy favorable para el PSOE que lejos de demorar y dilatar el tema sine die opta por sumarse a la propuesta favorablemente. EI PSOE se implica y se compromete con la aprobación de la ley, y El Periódico de Aragón se suma a esa implicación voluntaria con la última propuesta para la Ley de Igualdad.

El quinto artículo plantea que la formación de la mujer superior a la del hombre y en cambio su retribución inferior a la del hombre, de al menos 15\%. Esta crónica enviada desde Bruselas por un corresponsal varón, recoge datos del Informe Europeo. Ésta es una de las más indignantes paradojas que España y otros países de la UE viene padeciendo. 
Por razones obvias, el informe no incluye a las mujeres de otros continentes, porque ellas ni siquiera han podido alcanzar los mismos niveles de formación. Recuérdese la proporción existente en la universidad, dato trasladado por la vicerrectora africana, era de una proporción 60/1000.

Éste es un capítulo pendiente y El Periódico de Aragón hace bien en incluirlo en su agenda periodística, porque debe ser necesariamente también un item de la agenda política. El Periódico de Aragón se destaca en muchos aspectos periodísticos y políticos.

Este sexto artículo, titulado La discapacidad y el empleo bien podría haberse titulado: La doble discriminación. Viene a decir que si las tasas de desempleo, son más altas para la mujer que para el hombre, cuando existe una discapacidad la mujer sufre una doble discriminación. El sumatorio es inagotable y El Periódico de Aragón lo recoge muy adecuadamente.

El artículo número siete de El Periódico de Aragón analizado, permite constatar con un testimonio en forma de entrevista otra discriminación femenina. En esta ocasión se trata de una mujer joven que se ha visto obligada a denunciar su caso y considera que tener que llegar a los juzgados no es la mejor forma de resolver los conflictos, especialmente si están basados en una discriminación negativa basada en la maternidad. Este tipo de discriminación femenina hacia la maternidad no contribuye mucho, entre otras cosas, a la gran aspiración a tener un índice de natalidad superior. Las incongruencias se pagan, y ésta es una de ellas que este medio se encarga de constatar en primera persona, con nombre, apellido e imagen a color.

El último artículo analizado en este medio hace referencia al Día Internacional de las Mujeres, y es la opinión de una lectora cuya máxima preocupación yace en la conciliación real de la vida familiar y la vida laboral, además de incidir nuevamente en la menor retribución femenina ante el mismo puesto de trabajo. Es una carta centrada y planteada sin muchos ambages que va directa al grano y a tocar los dos aspectos que para la remitente son más importantes. En este sentido es posible y de esperar que la Ley de lgualdad venga a paliar algunas de las deficiencias legales que la Ley de Conciliación presenta.

Los dos periódicos aragoneses analizados han sido capaces de ofrecer una posición y un posicionamiento muy correcto y comprometido. Aunque con matices distintos, el Día Internacional de las Mujeres Trabajadoras muestra una agenda periodística, con bastante consonancia con la agenda pública y política española, europea e internacional, dado que ha de recordarse que el año que se analiza (2007) fue declarado el Año Internacional de la Igualdad.

Esta consonancia de agendas tanto periodística como política, tiene aún mas importancia si se considera que para el MTAS no insertó publicidad institucional en estos dos periódicos autonómicos, mientras que sí lo hizo en los periódicos nacionales, hecho que podría haber 
reforzado la agenda política, y que no fue forzada en absoluto la agenda periodística aragonesa, dado que esta publicidad no aparecía.

Las diferencias son ligeras. El Heraldo de Aragón presenta un artículo menos, pero utiliza más páginas impares que El Periódico de Aragón, proporción inversa a cómo presentan los artículos en las páginas pares. Utilizan ambos secciones especiales y El Periódico de Aragón hace un mayor despliegue gráfico que El Heraldo de Aragón.

En todo caso, ambos han mostrado una gran sensibilidad y compromiso con el progreso social, en lo que al tratamiento del item "mujer" se refiere en el Día Internacional de las Mujeres Trabajadoras.

\section{Bibliografía}

Aguilera, O. (1990): Las ideologías en el periodismo, Madrid, Paraninfo.

Balle, F. (1991): Comunicación y sociedad. Evolución y análisis comparativo de los medios. Santa Fe de Bogotá, Tercer Mundo editores.

Bardin, L. (1986): Análisis de contenido, Madrid, Akal. Publicado en francés (1977) por Presses Universitaires de France. Trad. César Suárez.

Barthes R.:

- (1969): Elementos de Semiología, Madrid, Alberto Corazón, Ed.

- (1987): El susurro del lenguaje, Barcelona, PAIDÓS.

Berger, P. y Luckmann, T. (1989): La construcción social de la realidad, Buenos Aires, AMORRORTU Editores. Título original: The social construction of reality, (1968) by Doubleday \& Co., Garden City, Nueva York. Traducción de Silvia Zuleta.

Blanco, D. y Bueno, R. (1983): Metodología del análisis semiótico, Lima, Editorial Universo, S.A.

Bourdieu, P. (1980): Qué significa hablar? Economía de los intercambios lingüísticos, Madrid AKAL.

Conde, F. (1990): "Un ensayo de articulación de las perspectivas cuantitativa y cualitativa en la investigación social". REIS, Madrid, no 51:91-117, julio-septiembre.

Dader, J. L.: 
- (1992): "La canalización o fijación de la "agenda" por los medios", en Opinión Pública y Comunicación Política, Madrid, Eudema Universidad, de Alejandro Muñoz Alonso, et. al.: 294-316.

- (2000). "La "mujer" como categoría emergente en la producción de las noticias: pros y contras de una nueva visibilidad periodística", Cuadernos de Información y Comunicación, no 5, pp. 23-37.

Dijk, van T. A. (1990): La noticia como discurso. Comprensión, estructura y producción de la información, Barcelona, Paidós Comunicación. Título original: News as Discourse, Lawrence Erlbaum Associates, Publishers. Traducción de Guillermo Gal.

Enzenberger, H.M. (1974): Elementos para una teoría de los medios de comunicación, Barcelona, Anagrama.

García Ferrando, J. (1995): Socioestadística. Introducción a la estadística en sociología, Madrid, Alianza Universidad Textos.

Greimas, A.J. 1980): Semiótica y ciencias sociales. Madrid Fragua Editorial. Título original Sémiotique et sciences sociales (1976), París, Editions du Seuil. Traducción : J. Adolfo Arias Muñoz.

Hernando, B. M. (1990): Lenguaje de la prensa, Madrid, Eudema.

Ibáñez, J. (1990):. “Técnicas avanzadas en investigación social”, Barcelona, Suplementos ANTHROPOS, 22:143-4, octubre.

León, J. L. (1996): Los efectos de la publicidad, Barcelona, Ariel.

López-Escobar, E.; Llamas, J. P. y McCombs,M. (1996): "Una dimensión social de los efectos de los medios de difusión: agenda-setting y consenso", en Comunicación y Sociedad, vol. IX, no 1 y 2, pp. 91-125.

Noelle-Neumann, E. (1973): "Kumulation, Konsonanz und Öffentilichkeiteitseffeckt. Ein neuer Ansatz zur Analyse der Wirkung der Massenmedien", Publizistik, Vol. 18, pp. 26-55.

McCombs, M., \& SHAW, D.L. (1972): "The agenda-setting function of the mass media" Public Opinion Quarterly, 36: 176-185

Recio, F. (1994): "Análisis del discurso y teoría psicoanalítica", en Delgado, J.M. Métodos y Técnicas cualitativas de investigación en Ciencias Sociales, Madrid, Editorial SÍNTESIS, pp. 481-91. 
Stubbs, M. (1987): Análisis del discurso, Madrid, Alianza Psicología.

Wolf, M. (1994): La investigación de la comunicación de masas, Barcelona, Paidós. Título original: Teorie delle comunicazione di massa (1990), Bompiani, Milán. Traducción de Carmen Artal.

\section{Forma de citar este artículo en bibliografías}

GÓMEZ y PATIÑO, M. (2013): "La mujer en la prensa aragonesa. Análisis de los periódicos de referencia.", en Revista PANGEA, 3, páginas 183 a 205. Red Académica Iberoamericana de Comunicación. Recuperado el _ de _ _ de 2_ de:

http://www.revistapangea.org 